\title{
A clinical study on the surgical management of fracture shaft femur in children and adolescents by using Ender's nail
}

\author{
Raghu Kumar J., Sri Harsha Gutta*
}

Department of Orthopedics, JJM Medical College, Davangere, Karnataka, India

Received: 31 July 2016

Revised: 03 August 2016

Accepted: 16 August 2016

\section{*Correspondence:}

Dr. Sri Harsha Gutta,

E-mail: gsriharsha07@gmail.com

Copyright: (C) the author(s), publisher and licensee Medip Academy. This is an open-access article distributed under the terms of the Creative Commons Attribution Non-Commercial License, which permits unrestricted non-commercial use, distribution, and reproduction in any medium, provided the original work is properly cited.

\begin{abstract}
Background: Femoral shaft fractures account for $1.6 \%$ of all pediatric bony injuries. Current treatment options include early spica casting, traction, external fixation, open reduction and internal fixation with plating, flexible intramedullary nails and intramedullary rods. Experience of many clinicians has shown that children with diaphyseal fractures do not always recover with conservative treatment. Ender rod fixation in the paediatric population is simple, effective and minimally invasive. It allows stable fixation, rapid healing and a prompt return of the child to normal activity. The objective of the study was to evaluate the functional outcome of the pediatric femur shaft fractures with Ender's intramedullary nailing.

Methods: 20 patients aged 5 to 16 years with fracture shaft of the femur treated with retrograde flexible intramedullary nailing at Bapuji hospital attached to JJM Medical College, Davangere in the period from September 2014 to August 2015 were included in the study.

Results: All patients were followed until fracture union occurred. The follow up period ranged from 6 months to 1 year. Results were analysed both clinically and radiologically. 1 case united within 8 weeks, 14 cases in 10 weeks and 5 cases in 12 weeks. Out of 20 cases there is limb length discrepancy in 6 cases, infection in 2 cases, nail back out in 2 cases, varus malalignment in 2 cases, valgus malalingment in 3 cases, anterior angulation in 6 cases and rotational malalignment in 2 cases..

Conclusions: Closed intramedullary nailing is an efficient method and does not expose the patient to an undue risk of infection or non-union. There is also no risk of limb length discrepancy and the angulation and rotational malalignment are within the acceptable limits. This safe procedure can be recommended in children with multiple injuries co-existent head injury and in age groups 5 to 16 years.
\end{abstract}

Keywords: Femoral shaft fractures, Spica casting, Flexible, Intramedullary nails, Ender rod

\section{INTRODUCTION}

Femoral shaft fractures account for $1.6 \%$ of all pediatric bony injuries. ${ }^{1}$ Current treatment options include early spica casting, traction, external fixation, open reduction and internal fixation with plating, flexible intramedullary nails and intramedullary rods. ${ }^{2}$ There is little controversy over the treatment of infants and toddlers with femoral shaft fractures by using spica casting. ${ }^{3}$ Difference of opinion exist for those patients who are too old for early spica casting and yet too young for adult type of treatment with a reamed rod. In children fractures of the femoral shaft are commonly treated by various types of traction for about 3 weeks, followed by plaster immobilisation. Time and experience of many clinicians have shown that children with diaphyseal fractures do not always recover with conservative treatment. Angulation, malrotation and shortening are not always corrected effectively. ${ }^{4}$ Plating of the femoral shaft fracture offers rigid fixation, it requires a larger exposure with the potential for increased blood loss and scarring. It is a load bearing device and refracture is a risk. Antegrade nailing 
techniques have shown a risk of proximal femoral deformities and avascular necrosis of the femoral head. ${ }^{5,6}$ Elastic internal fixation in the form of flexible intramedullary nailing provides a healthy environment for fracture healing with some motion leading to increased callus formation. ${ }^{7}$ Ender rod fixation in the paediatric population is simple, effective and minimally invasive. It allows stable fixation, rapid healing and a prompt return of the child to normal activity. ${ }^{5}$

\section{METHODS}

In this study 20 patients aged 5 to 16 years with fracture shaft of the femur were treated with retrograde flexible intramedullary nailing at Bapuji hospital attached to JJM Medical College, Davangere, Karnataka in the period from September 2014 to August 2015 were included.

\section{Inclusion criteria}

Children and adolescent patients between 5 and 16 years with simple femoral fractures and type 1 and type 2 compound fracture.

\section{Exclusion Criteria}

Patients less than 5 years of age and more than 16 years of age, segmental fractures, type 3 compound fractures, very distal and very proximal fractures that preclude nail insertion, patients medically unfit for surgery.

Immediately after the patient was brought to casualty patients airway breathing circulation were assessed. Then a complete survey was carried out to rule out other significant injuries. Plain radiographs of AP and lateral views of the femur including hip and knee were taken.

\section{Surgical technique}

Under general anesthesia in younger children and spinal anesthesia in older children the patient was put in supine position on the fracture table. The opposite limb was held on a knee rest with the hip flexed to 90 degrees and abducted to 30 degrees and the knee in 90 degrees of flexion to allow visualisation of the entire femur in both AP and lateral views. The level of the insertion of the nails should be 2.5 to $3 \mathrm{cms}$ proximal to the distal femoral physis in the AP views and it should be in the middle of the cortex in the lateral views. Incision of about 2 to $3 \mathrm{cms}$ is put on the medial and lateral aspects of the thigh at the site of insertion of the nail. Soft tissues were split and the bone was exposed on both sides. A hole was made in the cortex by using $4.5 \mathrm{~mm}$ drill bit and then a bone awl was used to widen the cortical hole in the bone. A gentle 30 degrees bend was placed in the nail with apex at what will be the level of the fracture. Next the rod tip was bent to facilitate placement and allow the rod to bounce off the opposite cortex at the time of insertion. Upon insertion the rod glances off the cortex as it advances towards the fracture site. Both medial and lateral rods were inserted to the level of the fracture site. At this point the fracture was reduced using longitudinal traction and closed manipulation. After the first rod was driven approximately 2 to $3 \mathrm{cms}$ across the fracture the 2nd rod was driven across the fracture. The two rods were then driven into the proximal end of the femur with one driven toward the femoral neck and other toward the greater trochanter. Fluoroscopy was then used to confirm satisfactory reduction of the fracture and to ensure that rods have not comminuted the fracture as they were driven into the proximal fragment. About $1 \mathrm{~cm}$ of the ends of the rod was left distal to the insertion hole for easy removal.
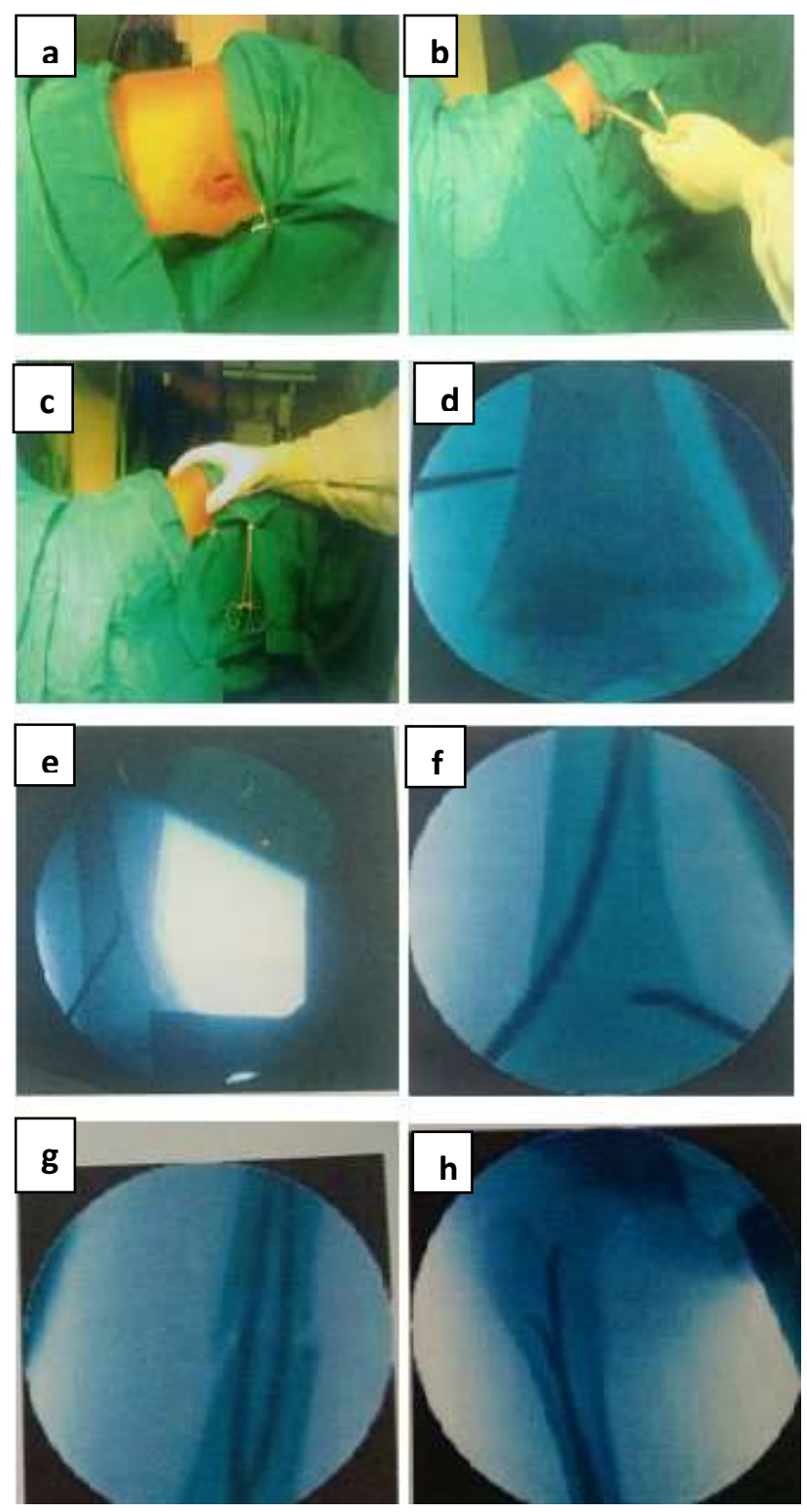

Figure 1 (a-h): Surgical procedure.

\section{RESULTS}

All patients were followed until fracture union occurred. The follow up period ranged from 6 months to 1 year. Results were analysed both clinically and radiologically. 
Table 1: Age wise distribution of cases.

\begin{tabular}{|lll|}
\hline Age in years & No. of cases & Percentage \\
\hline $\mathbf{5 - 8}$ & 8 & 40 \\
\hline $\mathbf{9 - 1 2}$ & 5 & 25 \\
\hline $\mathbf{1 3 - 1 6}$ & 7 & 35 \\
\hline
\end{tabular}

Out of 20 patients there were 16 males and 4 females. RTA was the commonest mode of injury. Right femur was involved in 12 cases and left involved in 8 cases. Out of 20 patients 16 cases were treated with closed reduction and 4 cases were treated with open reduction.

Table 2: Time of union in weeks.

\begin{tabular}{|lll|}
\hline Time of union & No of cases & Percentage \\
\hline 8 weeks & 1 & 5 \\
\hline 10 weeks & 14 & 70 \\
\hline 12 weeks & 5 & 25 \\
\hline
\end{tabular}

Table 3: Complications.

\begin{tabular}{|c|c|c|}
\hline Complications & No of cases & Percentage \\
\hline \multicolumn{3}{|l|}{ Limb lengthening } \\
\hline$<5 \mathrm{~mm}$ & 3 & 15 \\
\hline$>5 \mathrm{~mm}$ & 2 & 10 \\
\hline \multicolumn{3}{|l|}{ Limb shortening } \\
\hline$<5 \mathrm{~mm}$ & 5 & 25 \\
\hline$>5 \mathrm{~mm}$ & 1 & 5 \\
\hline Infection & 2 & 10 \\
\hline Nail back out & 2 & 10 \\
\hline \multicolumn{3}{|l|}{ Malalignment } \\
\hline a.Varus malaligment & 2 & 10 \\
\hline b.Valgus malalignment & 3 & 15 \\
\hline c. Anterior angulation & 6 & 30 \\
\hline $\begin{array}{l}\text { d. Rotational } \\
\text { malalignment }\end{array}$ & 2 & 10 \\
\hline $\begin{array}{l}\text { Bursa at the tip of the } \\
\text { nail }\end{array}$ & 2 & 10 \\
\hline $\begin{array}{l}\text { Sinking of the nail into } \\
\text { the medullary cavity }\end{array}$ & 1 & 5 \\
\hline
\end{tabular}
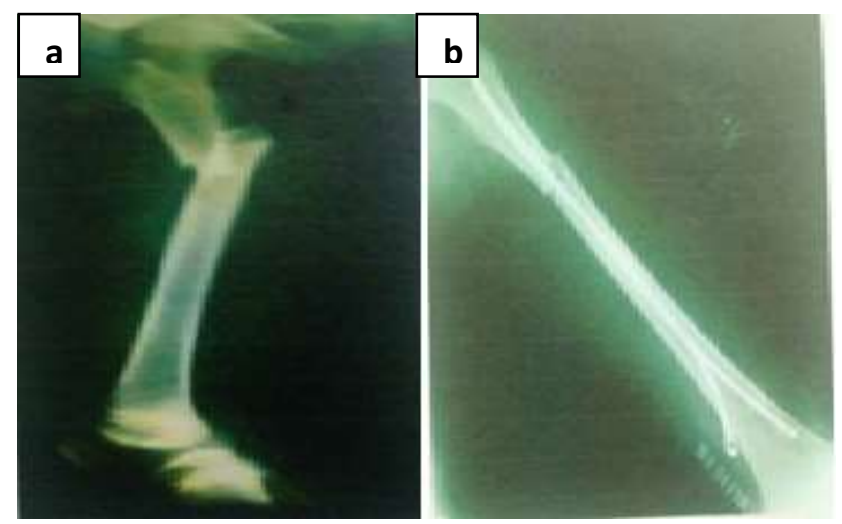

Figure 2 (a,b): Pre-operative and immediate postoperative appearance.
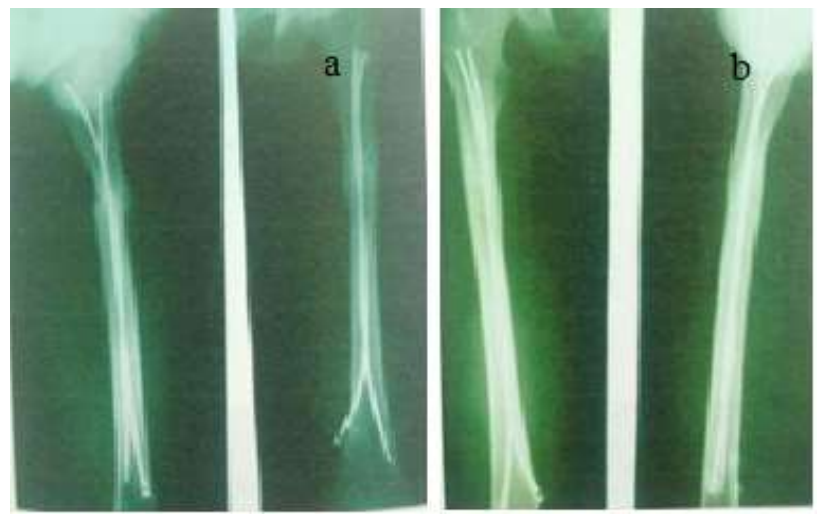

Figure 3: a) After 24 weeks b) After 36 weeks postoperatively.

\section{DISCUSSION}

This study was conducted to assess the results of Enders nail fixation of femoral fractures in children and adolescent patients. Many centres in the United States and Europe have reported the safety and efficacy of fixation of femoral fractures in children and adolescents by flexible intramedullary nail. Heinrich et al conducted a study on the 78 diaphyseal femur fractures stabilized with flexible intramedullary nails. ${ }^{4}$ They observed that the results obtained using flexible intramedullary nails are comparable to non-operative methods of treatment but with less disruption of family life. Canale TS et al observed that open reduction and plate fixation of femoral fractures in the age group of 5 to 10 years old children will result in femoral over growth and limb length discrepancy. They also observed that closed antegrade insertion of an intramedullary nail in children less than 10 years old may cause premature growth arrest of the greater trochanteric apophysis and thinning of the base of the femoral neck. ${ }^{8}$ Cramer et al concluded that operative treatment for paediatric femur fractures is becoming well accepted. They found that use of ender rod fixation in paediatric femur fracture allows the advantages of surgical fixation without many risks associated with other techniques. ${ }^{5}$ Lee SS et al conducted a biomechanical study to determine the effects of flexible intramedullary nail fixation on the simulated transverse and comminuted mid shaft fractures using two ender rods and observed that length and rotational control of mid shaft femur fractures with two divergent ender nails may be sufficient for early mobilisation. ${ }^{2}$ Karaoglu $\mathrm{S}$ et al concluded that in the adolescent age group ender nailing of femoral shaft fracture should be considered owing to the functional recovery with low morbidity and cost, providing early ambulation, early discharge from hospital and early return to school. ${ }^{9}$ The advantages of the present study include minimal scarring, closed reduction, load sharing device, fracture heals by secondary callus formation which is more stronger and re fracture is not a risk. It is also noted that the distal femoral and the capital femoral physis are left undisturbed as is the apophysis of the greater trochanter. The lateral ascending artery is also 
left undisturbed injury to which is associated with progressive coxa valga. ${ }^{10}$ In our study all the fractures united between 10-12 weeks, all patients regained full range of movements and no patient had significant limb length discrepancy (i.e $>2 \mathrm{~cm}$ ). Only 2 patients had superficial infection which was controlled with antibiotics. Surgical management of diaphyseal fractures of femur in children and adolescents by flexible intramedullary nailing is simple, effective and provides early mobilisation of the patients and rapid union. Functional results are excellent and complications are minimal. This procedure can be safely considered in the management of diaphyseal femur fractures in children and adolescents aged 5 to 16 years.

\section{CONCLUSION}

Closed intramedullary nailing is an efficient method and does not expose the patient to an undue risk of infection or non-union. It also helps in rapid union by means of preserving hematoma and limited soft tissue exposure. There is also no risk of limb length discrepancy and the angulation and rotational malalignment are within the acceptable limits. There is no risk of premature greater trochanteric arrest, progressive coxa valga, avascular necrosis of the femoral head and damage to the distal femoral physis when compared to the rigid nails. This mode of treatment reduces the length of hospital stay thus reducing the complications of prolonged immobilisation. This safe procedure can be recommended in children with multiple injuries co-existent head injury and in age groups 5 to 16 years.

Funding: No funding sources

Conflict of interest: None declared

Ethical approval: The study was approved by the institutional ethics committee

\section{REFERENCES}

1. Scherl S, Miller L, Lively N, Russinof S, Sullivan $\mathrm{M}$, Tornetta $\mathrm{P}$, et al. Accidental and non-accidental femur fractures in children. Clin Orthop and Rel Research. 2000;376:96-105.

2. Lee SS, Mahar T, Newton PO. Ender nail fixation of pediatric femur fractures. A Biomechanical analysis. J Pediatr Orthop. 2001;21:442-5.

3. Momberger N, Stevens P, Smith J, Santora S, Scott $\mathrm{S}$, Anderson J. Intramedullary nailing of femoral fractures in adolescents. J Pediatr Orthop. 2000;20:482-4.

4. Heinrich SD, Drvaric DM, Karr K, Macevan GD. The operative stabilisation of the pediatric diaphyseal femur fractures with flexible intramedullary nails: A Prospective analysis. J Pediatr Orthop. 1994;14:501-7.

5. Cramer KE, Tornetta $\mathrm{P}$, Spero CR, Alter S, Miraliakbar H, Teefey J. Ender rod fixation of the femoral shaft fractures in children. Clin Orthop and Rel Research. 2000;376:119-23.

6. Townsend DR, Hoffinger S. Intramedullary nailing of femoral shaft fractures in children via trochanteric tip. Clin Orthop and Rel Research. 2000;376:113-8.

7. Kasser JR, Beaty JH. Femoral shaft fractures. In Beaty JH and Kasser JR eds. Rockwood and Wilkins fractures in children, 5th edition, Philadelphia, Lippincott Williams and Wilkins; 2001: 941-980.

8. Canale TS, Tolo VT. Fractures of the femur in children. J Bone \& Joint Surg. 1995;77(2):294-315.

9. Karaoglu S, Baktir A, Tuncal M, Karakas ES, Sakir TM. Closed ender nailing of adolescent femoral shaft fractures. Injury. 1994;25(8):501-6.

10. Mileski R, Garvin KL, Huurman WW. Avascular necrosis of the femoral head after closed intramedullary nailing in an adolescent. J Pediatr Orthop. 1995;15:24-6.

Cite this article as: Raghu Kumar J, Gutta SH. A clinical study on the surgical management of fracture shaft femur in children and adolescents by using Ender's nail. Int J Res Orthop 2016;2:170-3. 